\title{
MiR-940 Inhibited Pancreatic Ductal Adenocarcinoma Growth by Targeting MyD88
}

\author{
Bin Song ${ }^{\mathrm{a}}$ Chaoxiong Zhang ${ }^{\mathrm{b}}$ Gang Li ${ }^{\mathrm{a}} \quad$ Gang Jin ${ }^{\mathrm{a}}$ Cong Liu ${ }^{\mathrm{c}}$ \\ aDepartment of Pancreatic Surgery, Changhai Hospital, Second Military Medical University, Shanghai, \\ bDepartment of Centre for Disease Prevention and Control, Chengdu Military Region, Chengdu, \\ 'Department of Radiation Medicine, Faculty of Naval Medicine, Second Military Medical University, \\ Shanghai, China
}

\section{Key Words}

MiR-940 • PDAC • MyD88 • Patients' survival

\begin{abstract}
Background: Pancreatic ductal adenocarcinoma (PDAC) is an almost universally lethal disease. Deregulation or dysfunction of miRNAs contribute to cancer development. The role of miR940 in PDAC remains unclear. Methods: The level of miR-940 in PDAC tissues and cell lines was measured by qRT-PCR. MiR-940 was over-expressed by miRNAs mimics transfection and reduced by miRNAs antisense oligonucleotides (ASO) transfection. Cell proliferation was analyzed by MTT assay and cell apoptosis was evaluated by FACS analysis. Targeted genes were predicted by a bioinformatics algorithm and confirmed by a dual luciferase reporter assay. Myeloid differentiation primary response gene (88) (MyD88) protein level was assayed by immunohistochemistry and Western blot analysis. Results: Low miR-940 level and high MyD88 protein level in PDAC tissues were both correlated with low survival rate. Up-regulation of miR-940 inhibited PDAC cell lines growth while down-regulation induced cell growth. The 3' UTR of MyD88 was targeted by miR-940. Conclusions: Low level of miR-940 and high level of MyD88 in PDAC promoted PDAC cells growth which might be related to the low survival rate of PDAC patients. MiR-940 exerted its effect by targeting MyD88.
\end{abstract}

Gang Jin,

and Cong Liu

\section{KARGER 125}




\section{Cellular Physiology and Biochemistry}

Cell Physiol Biochem 2015;35:1167-1177

\begin{tabular}{l|l}
\hline DOI: 10.1159/000373941 & C) 2015 S. Karger AG, Basel
\end{tabular}

Song et al.: MiR-940 Target MyD88 In PDAC

\section{Introduction}

Pancreatic ductal adenocarcinoma (PDAC) is one of the most aggressive and lethal cancer in humans. Annually, approximately 43,000 people are diagnosed (incidence 1012:100,000) with PDAC in the Unites States and the mortality rate of 36,800 , almost equals this number [1]. The patients with potentially resectable disease are a minority $(10 \%-$ $15 \%$ ) [2]. The median overall survival is less than 6 months and, despite surgery, the 5-year survival rate is a dismal 3 to $5 \%$, with chemotherapeutic options having only a limited impact. Cancer is a complex disease involving numerous genetic and epigenetic changes, thus as a better understanding of the molecular mechanism of PDAC is urgently needed to develop an effective diagnosis and treatment [3], these cancer related changes need to be investigated.

MicroRNAs (miRNAs) are a class of endogenous non-coding, single-stranded small regulatory RNA molecules, which are approximately 22 nucleotides in length [4]. MiRNAs inhibit translation via silencing mRNA molecules by cleaving mRNA after base-pairing to the 3' untranslated region of the target genes [5-7]. Previous studies indicated that miRNAs are not only involved in the pathogenesis of PDAC but also in the regulation of the response to chemotherapy. For example, miRNAs expression profiles detected in pancreatic tumor tissues are different from those identified in normal pancreas or in chronic pancreatitis [8]; additionally the miR-200 family has been shown to regulate epithelial to mesenchymal transition by targeting Zinc Finger E-box-binding 1 (ZEB1) and Zinc Finger E-box-binding 2 (ZEB2) and thus appears to have an important role in PDAC $[9,10]$. In addition, receptorinteracting protein 1 (RIP1), a mediator in cell survival and death signaling, which participates in the cancer's response to chemotherapy, has been found to be regulated by miRNAs. In lung cancer knockdown of RIP1 was associated with robust JNK activation [11,12]. Another study showed that the expression of miR-940 was substantially increased in RIP1 knockdown cells and that the knockdown of miR-940 restored MKP1 expression and attenuated cisplatininduced JNK activation and cytotoxicity [13].

Here we focused on the role of miR-940 in PDAC. We found that low miR-940 level in PDAC tissues was correlated with low survival rate. We also investigated the effects of upand down-regulation of miR-940 in PDAC cell lines. Many of miR-940-targeted genes were predicted, including MyD88. MyD88 is a very key adaptor protein, which mediates numerous biologically important signal transduction pathways in innate immunity [14-18]. Thus the role of MyD88 in PDAC was also investigated.

In conclusion, our data showed that low level of miR-940 in PDAC promoted PDAC growth via MyD88.

\section{Materials and Methods}

Patients

Surgical specimens from 78 PDAC patients and matched tumor-adjacent normal tissues were obtained postoperatively in 2009 from Department of General Surgery, Changhai Hospital, Second Military Medical University (Shanghai, China). All patients gave signed, informed consent for their tissues to be used for scientific research. Ethical approval for the study was obtained from Changhai Hospital, Second Military Medical University (Shanghai, China). All diagnoses were based on pathological and/or cytological evidence. The histological features of the specimens were evaluated by senior pathologists according to the World Health Organization classification criteria. Tissues were obtained before chemotherapy and radiotherapy and were immediately frozen and stored at $-80^{\circ} \mathrm{C}$ prior to qRT-PCR assay. 78 patients had been followed-up for 3 years and complete clinical data were electronically recorded.

\section{Cell culture}

HEK293, PANC1, SW1990 and HPDE6 were obtained from the Cell Bank of Chinese Academy of Science (Shanghai, China) and HEK293, PANC1, SW1990 were cultured in DMEM medium (Hyclone, South Logan, UT, USA) supplemented with 10\% fetal bovine serum (Hyclone, South Logan, UT, USA), 2 mM L-glutamine 


\section{Cellular Physiology and Biochemistry}

Cell Physiol Biochem 2015;35:1167-1177

DOI: $10.1159 / 000373941$

Published onime: February 06, 2015

Song et al.: MiR-940 Target MyD88 In PDAC
(C) 2015 S. Karger AG, Basel

www.karger.com/cpb

and $100 \mu \mathrm{g} / \mathrm{mL}$ penicillin/streptomycin (Bio Light, Shanghai, China) as described in previous studies [19, 20]. HPDE6 was cultured in keratinocyte serum-free medium supplemented by epidermal growth factor and bovine pituitary extract (Life Technologies, Inc, Grand Island, NY) [21].

\section{Real time $q-P C R$}

Real-time quantitative PCR analysis for miR-940 was performed by Shengong Company (Shanghai) using standard protocols on an Applied Biosystem's 7500 HT sequence Detection System. miR-940 expression was assessed using a mirVana ${ }^{\mathrm{TM}} \mathrm{qRT}$-PCR miRNA Detection Kit (Ambion, USA). The primers were designed and synthesized by Shengong Company (Shanghai). U6 as an internal control.

\section{MTT assay}

For MTT assay, $5 \times 10^{3}$ cells per well were seeded in triplicate in a 96-well plate with complete growth medium. Cells were counted over 5 days using the MTT assay (Promega, Fitchburg, WI, USA) as described previously [22-24]. The data was measured by Microtiter plate reader 570-nm filters (Promega, Fitchburg, WI, USA ).

\section{Apoptosis assay}

Cells from each group were harvested at $48 \mathrm{~h}$ post-transfection. Cells were resuspended at a density of $1 \times 10^{6}$ cells $/ \mathrm{mL}$ in PBS. After double staining with FITC-Annexin V and propidium iodide (PI) using the FITC Annexin V Apoptosis Detection Kit I (BestBio, Shanghai, China), cell were analyzed using FACScan flow cytometer (BD Biosciences) equipped with Cell Quest software (BD Biosciences). Annexin $\mathrm{V}^{+} \mathrm{PI}^{-}$cells were counted as apoptosis cells.

\section{MicroRNAs targets prediction}

TargetScanHuman (http://www.targetscan.org/vert_61/) [25-28] was applied to identify the potential target of miR-940.

\section{MiRNAs antisense, miRNAs mimics, oligonucleotides}

MiRNA-940 function was explored by cell transfection experiment. MiR-940 mimics (Cat. no. MSY0004983), miR-940 ASO (Cat. no. MIN0004983) and negative control (Cat. no. MSY0002505) were purchased from Qiagen(Venlo, Limburg, the Netherlands). MiRNAs ASO, MiRNAs mimics, negative control (NC) were transfected into cells at a concentration of 50nM using Lipofectamine 2000 (Invitrogen, Canada) transfection reagent according to the manufacturer's instructions. $48 \mathrm{~h}$ later cells were collected for further experiments.

\section{MyD88 3'UTR reporter analysis}

The MyD88 3'UTR reporter plasmid (pRL-MyD88) was constructed by Shengong Company (Shanghai, China). Mutation in the miR-940 seed regions of the MyD88 3'UTR was generated using QuikChang Multi site -directed mutagenesis kit (Promega, Fitchburg, WI, USA). RL reporter plasmids (3.6fmol) and pGL3control (500ng for normalization) (Promega, Fitchburg, WI, USA) were transfected with Lipofectamine 2000 (Invitrogen, Canada) into HEK293 $\left(6 \times 10^{4}\right.$ cells per well). Cells were collected after $48 \mathrm{~h}$ for assay using the Dual Luciferase reporter assay system (Promega, Fitchburg, WI, USA) [29].

\section{Western blot and antibodies}

Tumor tissues were collected, lysed, and blotted as described previously [30]. Membranes were blocked with blocking solution (5\% skim milk in TBST) and incubated with primary antibody, followed by the incubation with appropriate HRP-conjugated secondary antibody. The MyD88 antibody (anti-MyD88) was purchased from Santa Cruz Biotechnology, Inc. The densitometry of Western blot results was measured using ImageJ software.

\section{Immunohistochemistry}

Briefly, 4- $\mu$ m thick sections were cut and anti-MyD88 antibody (Santa Cruz Biotechnology) was applied. Subsequent counterstaining was performed with hematoxylin. Immunostaining results for MyD88 were evaluated using a semi-quantitative scoring system as described previously [31], which calculated the 


\section{Cellular Physiology and Biochemistry}

Cell Physiol Biochem 2015;35:1167-1177

\begin{tabular}{l|l}
\hline DOI: $10.1159 / 000373941$ & (C) 2015 S. Karger AG, Basel
\end{tabular}

www.karger.com/cpb

Song et al.: MiR-940 Target MyD88 In PDAC

staining intensity and the percentage of positive cells. Immunohistochemistry (IHC) staining was scored according to the following criteria:,$- 0-10 \%$ of the nucleated cells stained,,$+ 10-40 \%$ stained, $++; 40-70 \%$ stained and,$+++ 70-100 \%$ stained. MyD88 expression was considered to be observed when score $\geq+$. Alternatively, IHC score of MyD88 expression was $(-\sim+)$ and $(++\sim+++)$, which represented low and high expression, respectively.

MyD88 mRNA expression in PDAC analysis

The data of MyD88 mRNA in PDAC was queried from Gene Expression Omnibus (GSE15471).

\section{Statistical Analysis}

Data were presented as the mean \pm s.d. from at least three independent experiments. The difference between groups were analyzed using two-tailed Student's $t$ test when only two groups were compared. The Wilcoxon matched-pairs signed rank test was used to determine if there was a statistically significant difference in the expression of miR-940 and MyD88 between matched pairs. The difference between groups were analyzed using ANOVA when three or more than three groups were compared. Correlation analysis was performed by two-tailed Person's correlation coefficient analysis. Patients' survival was determined by Kaplan-Meier analysis. Statistical analyses were performed using SPSS software (version 17.0 ). $\mathrm{P}<0.05$ was considered significantly different.

\section{Results}

Low miR-940 level in PDAC tissues was correlated with low survival rate

MiR-940 level was assayed by qRT-PCR analysis in 78 pairs of PDAC tissues and the matched tumor-adjacent normal tissues. We found that 61 of the 78 tissues samples showed lower miR-940 level than in the matched tumor-adjacent normal tissues (Fig. 1A). The mean level of miR-940 was lower in PDAC tissues than in matched tumor-adjacent normal tissues (Fig. 1B). To evaluate the clinical significance of this finding, we investigated whether the level of miR-940 was associated with overall survival in PDAC patients. To this end, the 78 PDAC patients, from whom the analyzed samples have been collected, were followed-up for 50 months. The median value of all 78 cases was chosen as the cutoff point for separating miR-940 high-expression cases from miR-940 low-expression cases. Survival curves showed that patients with high miR-940 levels (39 cases) had a significantly longer overall survival than patients with low miR-940 levels (39 cases)(Fig. 1C). We also assayed miR-940 level in PDAC cell lines and found that SW1990, and PANC1 cells expressed a lower level of miR-940 than pancreatic duct epithelial cell line, HPDE6 (Fig. 1D).

Overexpression of miR-940 inhibited PDAC cell lines growth and induce cells apoptosis

We investigated the role of miR-940 in vitro, by overexpressing the level of miR-940 through transfection of miR-940 mimics in PANC1 and SW1990 cells. The effectiveness of transfection was verified by qRT-PCR (Fig. 2B). The analysis of cell proliferation, by MTT assay $24 \mathrm{~h}$ post transfection, showed that the overexpression of miR-940 level inhibited the proliferation of the PANC1 and SW1990 cell lines. In addition, the evaluation of the effect of miR-940 on cell apoptosis in PANC1 and SW1990 cell by FACS revealed that overexpression of miR-940 led to increased cell apoptosis in both cell lines (Fig. 2C, D).

Reduction of miR-940 promoted PDAC cell lines proliferation and inhibited cell apoptosis

We also investigated the effect of the inhibition of miR-940 by transfecting PANC1 and SW1990 cells with miR-940 ASO, expressing the miR-940 anti-sense oligonucleotide (ASO) to transiently suppress miR-940. We found that miR-940 ASO transfection suppressed the miR-940 level in the both cell lines (Fig. 3A). Additionally, cells proliferation analysis by MTT assay after miR-940 ASO transfection revealed that the down-regulation of miR-940 mildly promoted cell proliferation in PANC1 and SW1990 cells (Fig. 3B). Next cell apoptosis was assayed by FACS analysis, and found that suppression of miR-940 reduced cell apoptosis cells in PANC1 and SW1990 cells (Fig. 3C, D). 


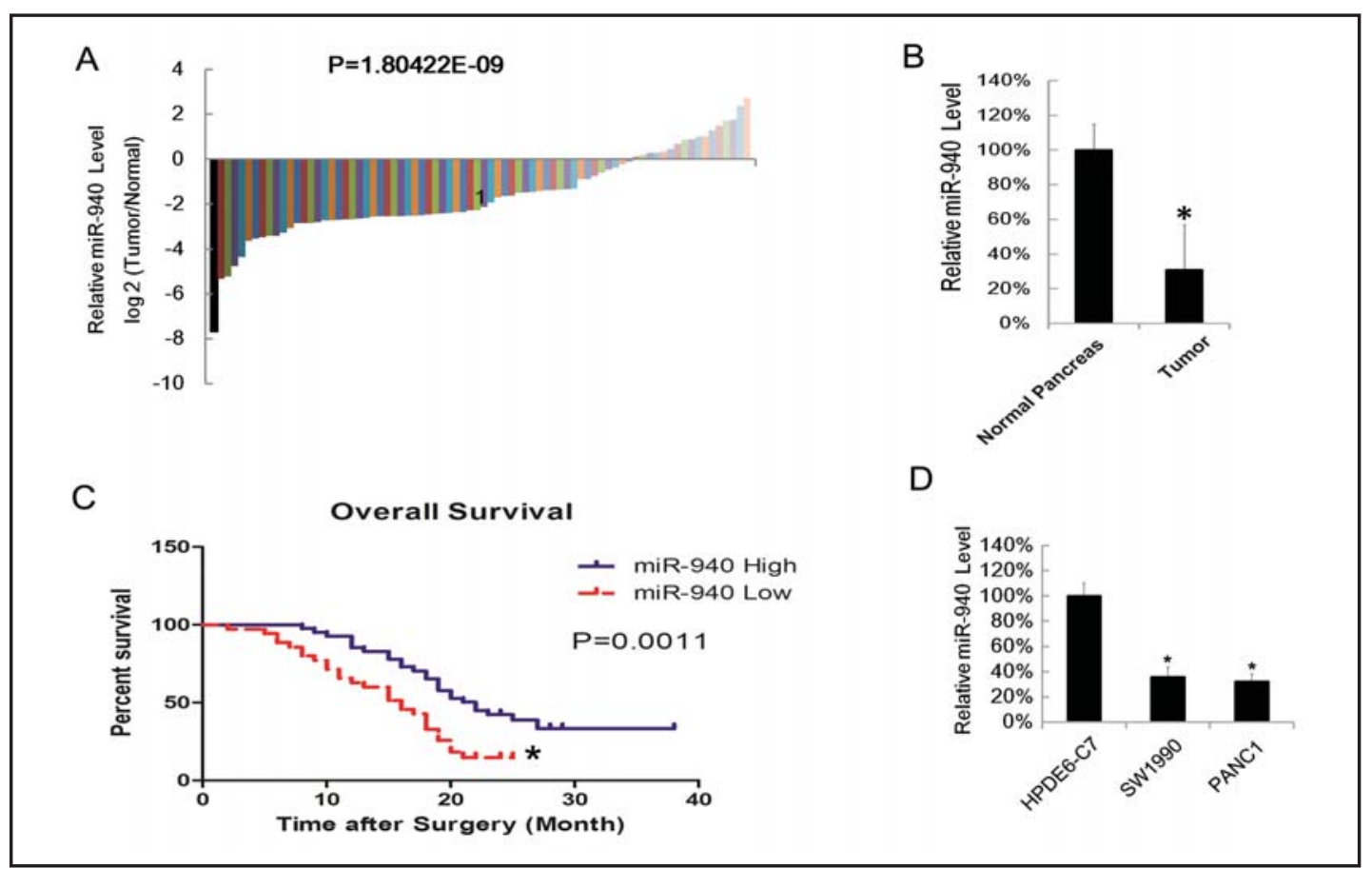

Fig. 1. Low miR-940 level in PDAC tissues was correlated with low survival rate. The miR-940 expression in 78 pairs of PDAC and in matched tumor-adjacent normal tissue specimens were analyzed by qRT-PCR. The difference in expression of miR-940 between PDAC and matched tumor-adjacent normal tissues were compared (A).The mean miR-940 expression in the 78 pairs PDAC and matched tumor-adjacent normal tissues (B). Kaplan-Meier plot of overall survival in PDAC patients post-operation according the expression of miR-940 (C). MiR-940 level in normal pancreas, PANC1, SW1990 and HEK293 cell lines were assayed by qRT-PCR. The miR-940 expression in HPDE6-C7 was arbitrarily defined as 100\% (D). All qRT-PCR experiment were performed in triplicate, Data are mean \pm s.d. of three separate experiments, ${ }^{*} \mathrm{P}<0.05$.

\section{MyD88 was targeted by miR-940}

We next explored the potential target genes of miR-940 by applying bioinformatics algorithm to predict miR-940-targeted genes. Many genes were predicted (data not shown), including the myeloid differentiation primary response gene (88) (MyD88). MyD88 is a key adaptor protein, which mediates numerous biologically important signal transduction pathway in innate immunity [14-18]. Because of its possible relevance to PDAC pathogenesis MyD88 was chosen for further investigation, and the binding site and mutated site in MyD88 were shown (Fig. 4A). The intact 3'UTR of MyD88 and its mutated version were cloned into a luciferase reporter plasmids, which were used for co-transfection with miR-940 into HEK293 cells. We found that miR-940 reduced the luciferase activity of wild type 3' UTR reporter, while the luciferase activity of reporter with mutated version was not significantly affected (Fig. 4B). Western blot analysis performed to confirm the relation between miR-940 and MyD88 at the protein level showed that MyD88 protein level was inhibited $48 \mathrm{~h}$ after miR-940 mimics transfection. Thus these data indicated that MyD88 was targeted by miR940 (Fig. 4C).

High MyD88 protein level in PDAC tissues was correlated with low survival rate

To confirm the role of MyD88 in PDAC. We examined the MyD88 level in 78 PDAC tissues specimens and the matched tumor-adjacent normal tissues specimens by immunohistochemistry (IHC). The MyD88 expression level was scored by comparison to the MyD88 level in normal tissues which was arbitrarily assigned a score of 1 . Six representative cases were selected to illustrate the results. The scores of MyD88 level in the six cases were 


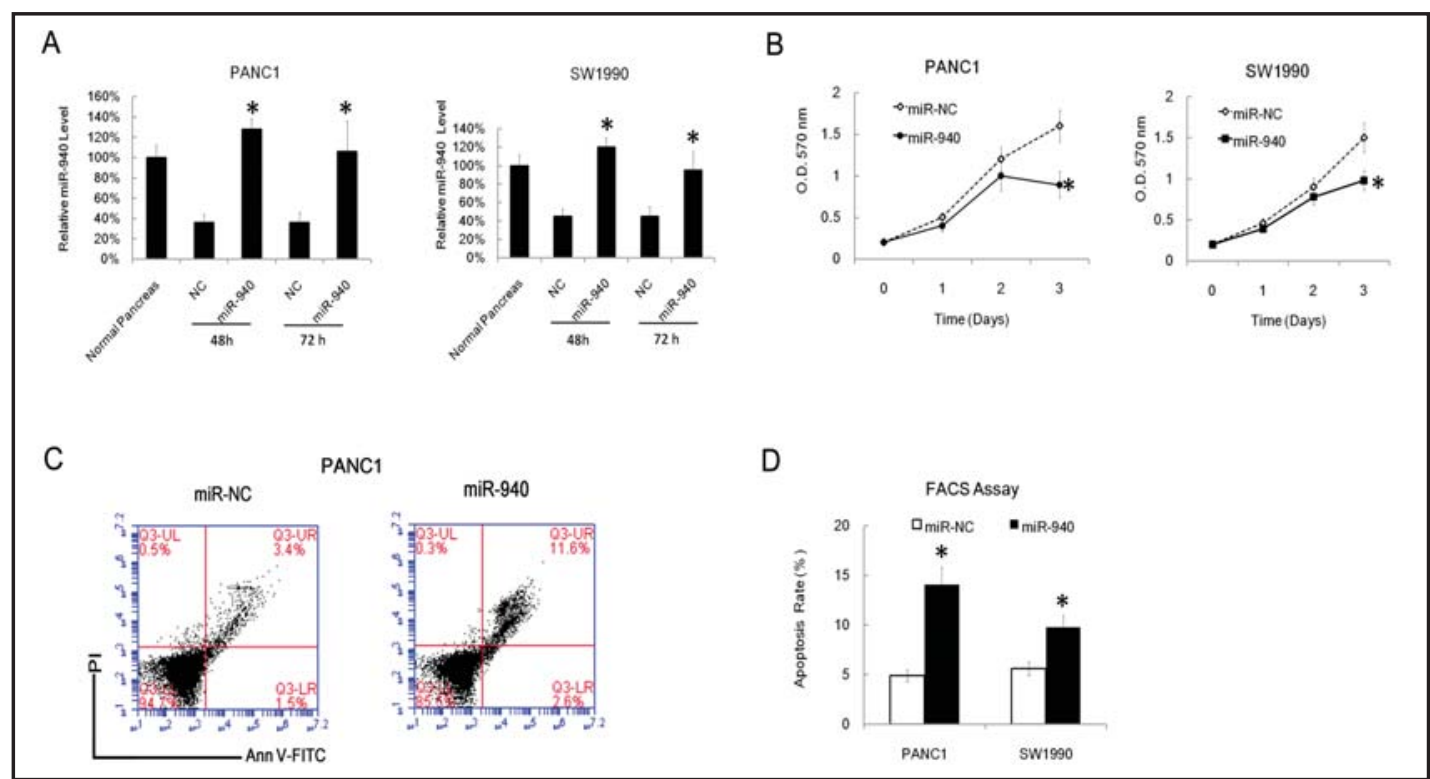

Fig. 2. Transfection with miR-940 mimics inhibited proliferation of PDAC cell lines and induced cells apoptosis. The level of miR-940 in PANC1, SW1990 cell lines were assayed by qRT-PCR $48 \mathrm{~h}$ or $72 \mathrm{~h}$ after miR-940 mimics transfection,. The miR-940 expression in normal pancreas tissue was arbitrarily defined as $100 \%$ (A). Following $48 \mathrm{~h}$ after miR-940 mimics transfection, the proliferation of PANC1 and SW1990 cells was assayed by MTT assay at the indicted time point (B). Following $48 \mathrm{~h}$ after miR- 940 mimics transfection, cell apoptosis of PANC1 was assayed by FACS analysis (C). Following $48 \mathrm{~h}$ after miR-940 mimics transfection, cell apoptosis rate of PANC1 and SW1990 was assayed by FACS analysis (D). All data are mean \pm s.d. of three separate experiments, ${ }^{*} \mathrm{P}<0.05$.

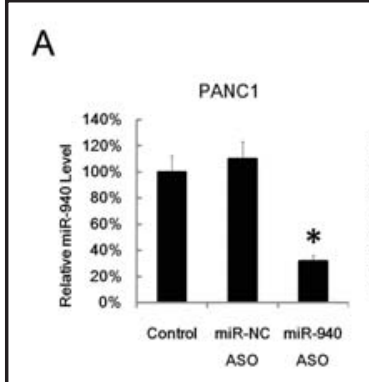

C

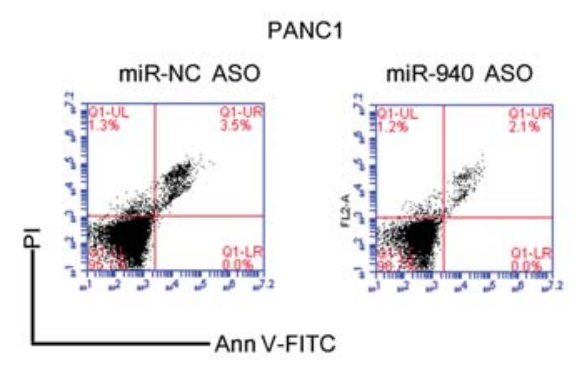

B
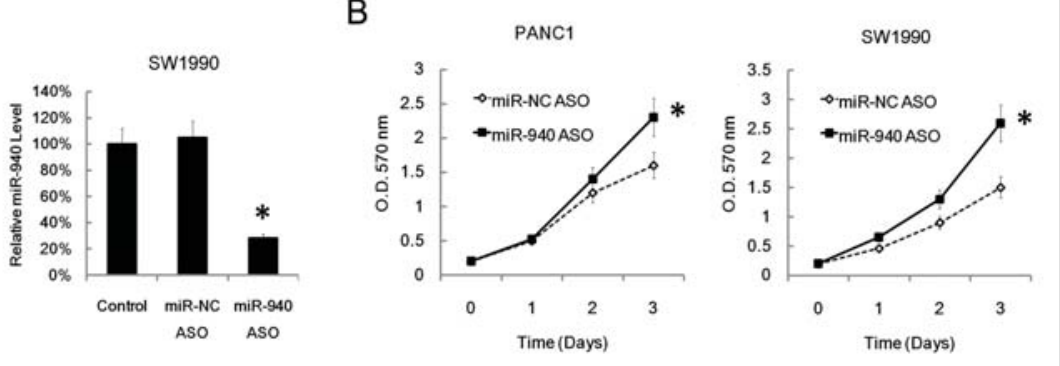

D

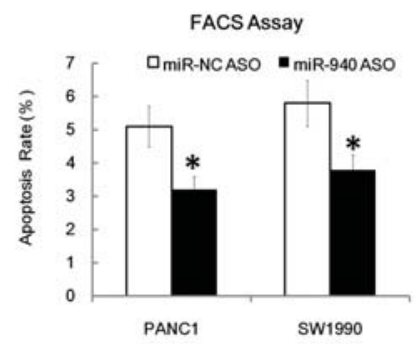

Fig. 3. Transfection with miR-940 inhibitors promoted proliferation of PDAC cell lines growth and inhibited cell apoptosis. PANC1 and SW1990 cell lines were transfected with miR-940 ASO. 48 h later miR-940 level in PANC1 and SW1990 cell lines was assayed by qRT-PCR. MiR-940 level in blank control was arbitrarily defined as 100\%(A). Following $48 \mathrm{~h}$ after miR-940 ASO transfection, the proliferation of PANC1 and SW1990 cells was analyzed by MTT at the indicated time point (B). Following $48 \mathrm{~h}$ after miR-940 ASO transfection, cell apoptosis of PANC1 was assayed by FACS analysis(C). Following $48 \mathrm{~h}$ after miR-940 mimics transfection, cell apoptosis rate of PANC1 and SW1990 was assayed by FACS analysis (D). All data are mean \pm s.d. of three separate experiments. ${ }^{*} \mathrm{P}<0.05$. 
Fig. 4. Target genes of miR-940 were predicted and confirmed. Putative targeted genes were predicted by TargetScanHuman, the binding site of putative targeted gene, and mutated site of miR-940 are shown (A). The RL reporter plasmids (RL-control, RLMyD88, RL-mutated MyD88) and miR-940 or miRNC were co-trans-

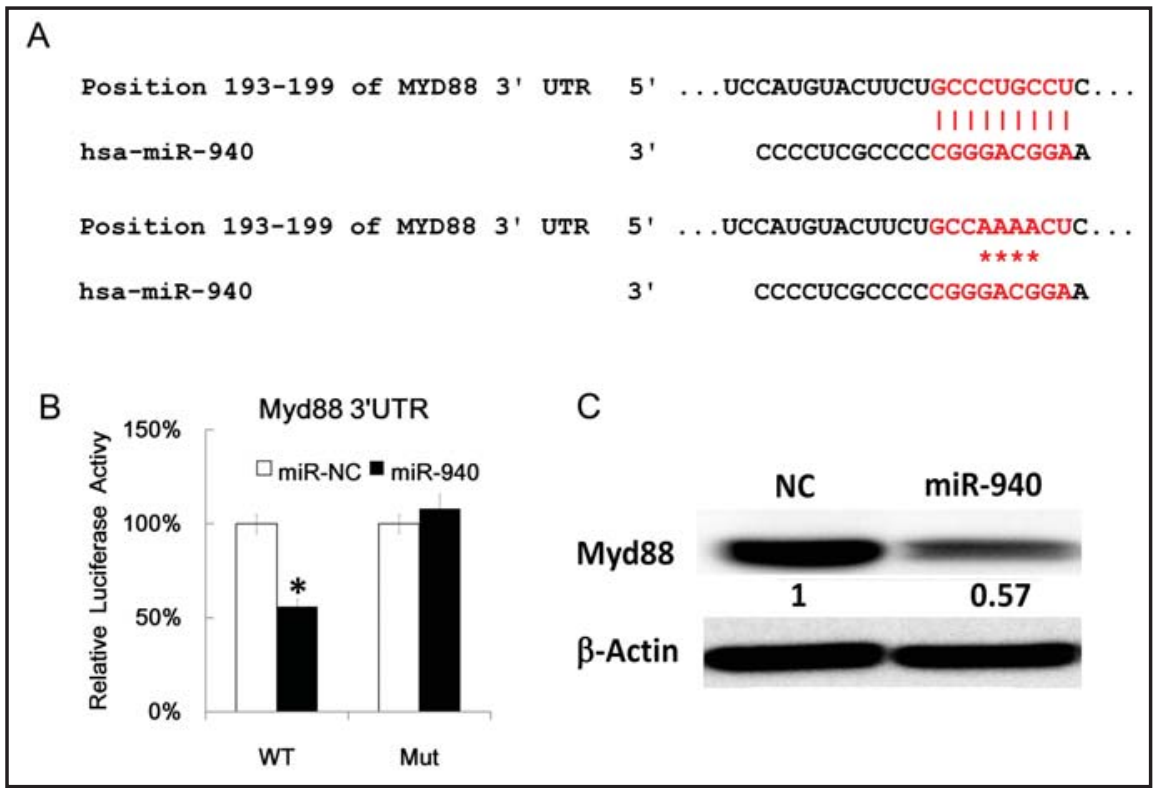

fected into HEK293 cells, along with a firefly luciferase reporter (pGL control) for normalization. Luciferase activities were measured after $48 \mathrm{~h}$. Then the ratio of RL activity of firefly luciferase activity in the miR-940 treated group were calculated and compared with the ratio in the miR-NC group (which was arbitrarily defined as 100\% ) (B). Following $60 \mathrm{~h}$ after miR-940 mimics transfection, MyD88 protein levels were assayed by Western blotting (C). Data are mean \pm s.d. of three separate experiments, ${ }^{*} \mathrm{P}<0.05$.

shown at the bottom of IHC images in Fig. 5A. The first three cases showed conspicuously higher MyD88 expression, there were 67, of 78 pairs of PDAC tissues specimens and matched-adjacent normal tissue specimens analyzed, with higher MyD88 level in the PDAC tissues than in normal control (Fig. 5B). The evaluation of the mean expression level revealed that the mean MyD88 expression in 78 PDAC tissues was higher than that of the matched tumor-adjacent normal tissues (Fig. 5C). Additionally, we assessed the clinical significance of MyD88 over-expression in PDAC, by evaluating whether the levels of MyD88 expression were associated with overall survival in 78 PDAC patients who were followed up for 50 months. After measuring MyD88 expression, the median value of all 78 case was chosen as the cutoff point for separating MyD88 high expression cases from MyD88 low expression cases. Kaplan-Meier curves indicated that patients with high MyD88 expression had a significantly shorter overall survival $(p=0.0026)$ than those with low MyD88 expression. The (Fig. 5D). Next we explored Gene Expression Omnibus (GEO) for analysis of MyD88 mRNA expression in PDAC. And found that MyD88 expression in tumor tissues were higher than in adjacent normal tissue $\left(p=3.14 \times 10^{-7}\right)$ (Fig. $5 \mathrm{E}$ )

\section{MyD88 over-expression partly reduced the inhibitory effect of miR-940}

The correlation between miR-940 and MyD88 was analyzed by Pearson's correlation coefficient analysis. The results revealed that MyD88 is inversely correlated with miR-940 in PDAC tissues (Fig. 6A). Furthermore, proliferation analysis of cells over-expressing MyD88 after miR-940 mimics transfection, by MTT assay, revealed that MyD88 over-expression partly reduced the anti-proliferative effect of miR-940 on these cells (Fig. 6B).

\section{Discussion}

In this study, we found that low level of miR-940 level and high level of MyD88 protein in PDAC tissues were both correlated with low survival rate in PDAC patients. We also found 


\section{Cellular Physiology Cell Physiol Biochem 2015;35:1167-1177 and Biochemistry \begin{tabular}{l|l}
$\begin{array}{l}\text { DOI: 10.1159/000373941 } \\
\text { Publisned onine: Feoruary 06, } 2015\end{array}$ & $\begin{array}{l}\text { O 2015 S. Karger AG, Basel } \\
\text { www.karger.com/cpb }\end{array}$ \\
\cline { 2 - 3 }
\end{tabular}

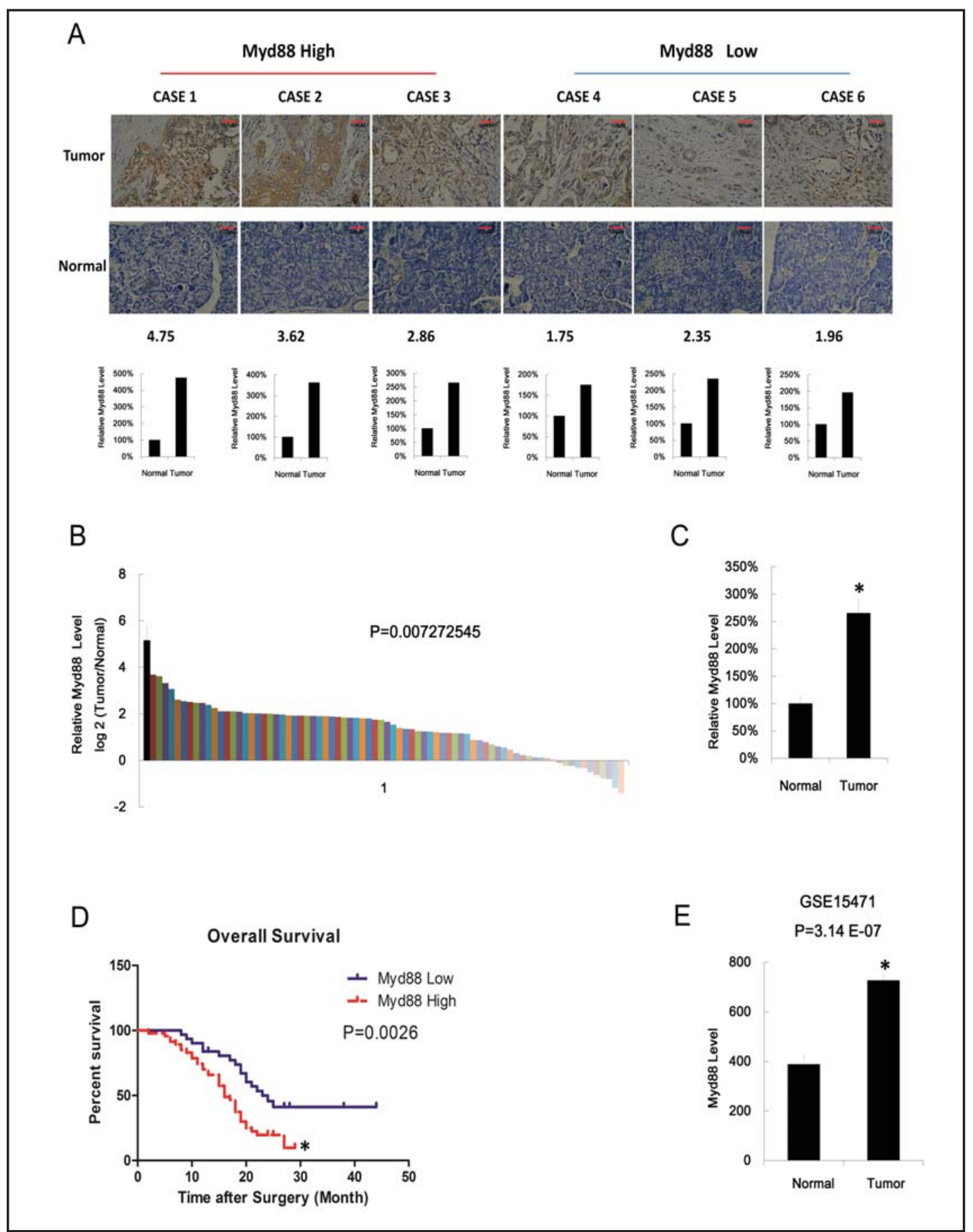

Fig. 5. High MyD88 protein level in PDAC tissues was correlated with low survival rate. MyD88 protein levels in 78 pairs of PDAC tissue samples and matched tumor-adjacent normal samples were assayed by IHC analysis. Six representative cases are shown. The MyD88 expression level was scored by comparison to the MyD88 level in normal tissues, which was arbitrarily assigned a score 1.Six representative cases are shown. The scores of the MyD88 level in these six cases are shown at the bottom of the IHC images (A). MyD88 protein levels in the 78 pairs of PDAC tissue samples and matched tumor-adjacent normal tissue samples were compared (B). The mean level of MyD88 in the 78 pairs of tissue samples (C). Kaplan-Meier plot of overall survival in PDAC patients post-operation according the expression of MyD88 (D). MyD88 expression was higher in the PDAC tissue were higher than in adjacent normal tissue (GSE15471) (E). Data are mean \pm s.d. of three separate experiments. ${ }^{*} \mathrm{P}<0.05$. 


\section{Cellular Physiology and Biochemistry}

A

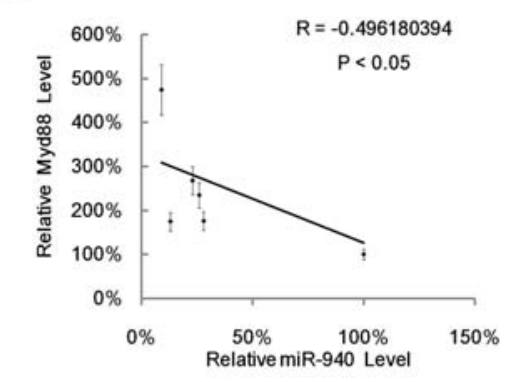

B

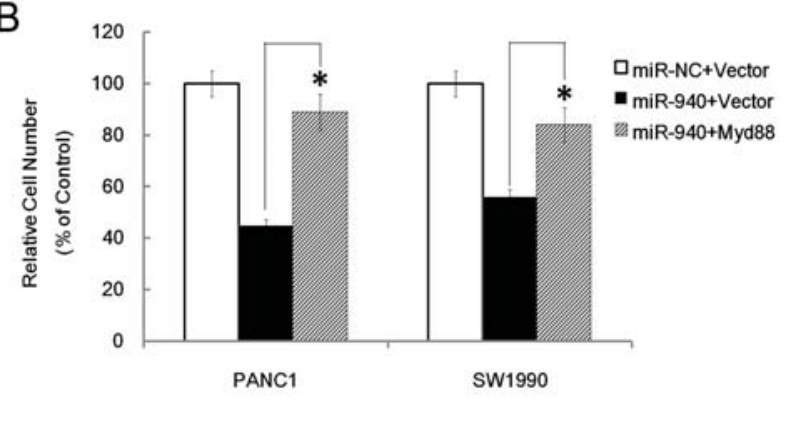

Fig. 6. MyD88 overexpression partly reduced the inhibitory effect of miR-940. Inverse correlation between miR-940 level and MyD88 protein level in the 6 PDAC tissue samples was revealed by Person's correlation coefficient analysis (A). PANC1 and SW1990 cells $\left(6 \times 10^{5}\right.$ cells/well) were transfected with miR-940 or miRNC (NC) separately, followed by transfection, $12 \mathrm{~h}$ later, with empty plasmid, or MyD88 overexpression plasmid (pcDNA3.1-MyD88). Then the MTT assay was performed. The OD value from MTT assay is presented as the relative cell number. The relative cell number in miR-NC+Vector (negative control) was defined as $100 \%$ (B).Data are mean \pm s.d of three separate experiments. ${ }^{*} \mathrm{P}<0.05$.

that overexpression of miR-940 inhibited the proliferation of PDAC cell lines and vice versa, and that 3' UTR of MyD88 was targeted by miR-940. Accordingly, we concluded that miR940 exerted its effect by targeting MyD88, and thus when the level of miR-940 in was low it promoted tumor cells growth, which in turn contributed to the observed low survival rate of PDAC patients.

Our data revealed the protection role of miR-940 in the carcinogenesis of PDAC. To the best of our knowledge, this maybe the first report about the role of miR-940 in PDAC. The role of miR-940 in prostate cancer was revealed by other study [32]. They found that miR-940 suppresses prostate cancer migration and invasion by regulating migration and invasion enhancer 1.

In our previous study, we found that miR-545 inhibited PDAC growth by targeting RIG-I [33]. It seemed that miR-940 exerted multifunction in different cancers, and the growth of PDAC was regulated by many miRNAs through different targeted genes

MyD88 is a very critical adaptor protein for TLR/IL-1R-mediated inflammatory response, and its mediated numerous biologically important signal transduction pathway in innate immunity [14-18].

It is known that TLR signaling were involved in pancreatic cancer associated inflammation [34]. TLR activation can accelerate pancreatic cancer development and TLR inhibition exerts protective effect. However, directly blocking MyD88 signaling results in paradoxically pro-tumorigenic outcomes [35, 36]. Because MyD88 inhibition in dendritic cells caused them to skew $\mathrm{CD}^{+} \mathrm{T}$ cells toward a $\mathrm{T}_{\mathrm{H}} 2$ profile, which in turn accelerated cancer progression by perpetuating inflammation [36]. Our study provide another method to regulate the expression of MyD88. Unlike direct MyD88 inhibition led catastrophic results, miR-940 could inhibit PDAC cells growth. Although our data came from in vitro experiment, we believed the role miR-940 in PDAC and in dendritic cells needed further investigation.

In conclusion, our study revealed the role of miR-940 in PDAC, and found low expression of miR-940 in PDAC cell lines promoted cell proliferate by MyD88. We hoped that our study may provide some hint for other PDAC research.

\section{Disclosure Statement}

The authors have declared that no competing interests exist. This work was supported by the grants from Natural Science Foundation of Shanghai, China (No. 12ZR1454000).

\section{KARGER}




\section{Cellular Physiology and Biochemistry}

Cell Physiol Biochem 2015;35:1167-1177

\begin{tabular}{l|l}
\hline DOI: $10.1159 / 000373941$ & (c) 2015 S. Karger AG, Basel
\end{tabular}
\begin{tabular}{l|l} 
Publisned online: February 06, 2015 & www.karger.com/cpb \\
\hline
\end{tabular}

Song et al.: MiR-940 Target MyD88 In PDAC

\section{Reference}

1 Jemal A, Siegel R, Ward E, Hao Y, Xu J, Thun MJ: Cancer statistics, 2009. CA Cancer J Clin 2009;59:225-249.

- Sener SF, Fremgen A, Menck HR, Winchester DP: Pancreatic cancer: A report of treatment and survival trends for 100,313 patients diagnosed from 1985-1995, using the national cancer database. J Am Coll Surg 1999;189:1-7.

- 3 Dang Z, Xu WH, Lu P, Wu N, Liu J, Ruan B, Zhou L, Song WJ, Dou KF: Microrna-135a inhibits cell proliferation by targeting bmi1 in pancreatic ductal adenocarcinoma. Int J Biol Sci 2014;10:733-745.

-4 Ambros V: Micrornas: Tiny regulators with great potential. Cell 2001;107:823-826.

5 Kim VN, Han J, Siomi MC: Biogenesis of small rnas in animals. Nat Rev Mol Cell Biol 2009;10:126-139.

6 Bartel DP: Micrornas: Target recognition and regulatory functions. Cell 2009;136:215-233.

7 Valencia-Sanchez MA, Liu J, Hannon GJ, Parker R: Control of translation and mrna degradation by mirnas and sirnas. Genes Dev 2006;20:515-524.

8 Park JY, Helm J, Coppola D, Kim D, Malafa M, Kim SJ: Micrornas in pancreatic ductal adenocarcinoma. World J Gastroenterol 2011;17:817-827.

-9 Gregory PA, Bert AG, Paterson EL, Barry SC, Tsykin A, Farshid G, Vadas MA, Khew-Goodall Y, Goodall GJ: The mir-200 family and mir-205 regulate epithelial to mesenchymal transition by targeting zeb1 and sip1. Nat Cell Biol 2008;10:593-601.

-10 Wellner U, Schubert J, Burk UC, Schmalhofer O, Zhu F, Sonntag A, Waldvogel B, Vannier C, Darling D, zur Hausen A, Brunton VG, Morton J, Sansom O, Schuler J, Stemmler MP, Herzberger C, Hopt U, Keck T, Brabletz S, Brabletz T: The emt-activator zeb1 promotes tumorigenicity by repressing stemness-inhibiting micrornas. Nat Cell Biol 2009;11:1487-1495.

11 Festjens N, Vanden Berghe T, Cornelis S, Vandenabeele P: Rip1, a kinase on the crossroads of a cell's decision to live or die. Cell Death Differ 2007;14:400-410.

$\$ 12$ Kaiser WJ, Offermann MK: Apoptosis induced by the toll-like receptor adaptor trif is dependent on its receptor interacting protein homotypic interaction motif. J Immunol 2005;174:4942-4952.

13 Wang Q, Shi S, He W, Padilla MT, Zhang L, Wang X, Zhang B, Lin Y: Retaining mkp1 expression and attenuating jnk-mediated apoptosis by rip1 for cisplatin resistance through mir-940 inhibition. Oncotarget 2014;5:1304-1314.

14 Warner N, Nunez G: Myd88: A critical adaptor protein in innate immunity signal transduction. J Immunol 2013;190:3-4.

15 Yamamoto M, Sato S, Hemmi H, Hoshino K, Kaisho T, Sanjo H, Takeuchi O, Sugiyama M, Okabe M, Takeda $\mathrm{K}$, Akira S: Role of adaptor trif in the myd88-independent toll-like receptor signaling pathway. Science 2003;301:640-643.

-16 Hemmi H, Kaisho T, Takeuchi O, Sato S, Sanjo H, Hoshino K, Horiuchi T, Tomizawa H, Takeda K, Akira S: Small anti-viral compounds activate immune cells via the tlr7 myd88-dependent signaling pathway. Nat Immunol 2002;3:196-200.

17 Medzhitov R, Preston-Hurlburt P, Kopp E, Stadlen A, Chen C, Ghosh S, Janeway CA Jr: Myd88 is an adaptor protein in the htoll/il-1 receptor family signaling pathways. Mol Cell 1998;2:253-258.

18 Adachi O, Kawai T, Takeda K, Matsumoto M, Tsutsui H, Sakagami M, Nakanishi K, Akira S: Targeted disruption of the myd88 gene results in loss of il-1- and il-18-mediated function. Immunity 1998;9:143150 .

19 Wu N, Liu C, Bai C, Han YP, Cho WC, Li Q: Over-expression of deubiquitinating enzyme usp14 in lung adenocarcinoma promotes proliferation through the accumulation of beta-catenin. Int J Mol Sci 2013;14:10749-10760.

20 Wu N, Zhang C, Bai C, Han YP, Li Q: Mir-4782-3p inhibited non-small cell lung cancer growth via usp14. Cell Physiol Biochem 2014;33:457-467.

21 Ouyang H, Mou L, Luk C, Liu N, Karaskova J, Squire J, Tsao MS: Immortal human pancreatic duct epithelial cell lines with near normal genotype and phenotype. Am J Pathol 2000;157:1623-1631.

22 van Meerloo J, Kaspers GJ, Cloos J: Cell sensitivity assays: The mtt assay. Methods Mol Biol 2011;731:237245.

23 Liu C, Zhou C, Gao F, Cai S, Zhang C, Zhao L, Zhao F, Cao F, Lin J, Yang Y, Ni J, Jia J, Wu W, Zhou L, Cui J, Zhang W, Li B, Cai J: Mir-34a in age and tissue related radio-sensitivity and serum mir-34a as a novel indicator of radiation injury. Int J Biol Sci 2011;7:221-233. 


\section{Cellular Physiology and Biochemistry}

Cell Physiol Biochem 2015;35:1167-1177

\begin{tabular}{|l|l|}
\hline DOI: $10.1159 / 000373941$ & C 2015 S. Karger AG, Basel
\end{tabular}

Song et al.: MiR-940 Target MyD88 In PDAC

24 Han ZB, Yang Z, Chi Y, Zhang L, Wang Y, Ji Y, Wang J, Zhao H, Han ZC: Microrna-124 suppresses breast cancer cell growth and motility by targeting cd151. Cell Physiol Biochem 2013;31:823-832.

-25 Lewis BP, Burge CB, Bartel DP: Conserved seed pairing, often flanked by adenosines, indicates that thousands of human genes are microrna targets. Cell 2005;120:15-20.

26 Friedman RC, Farh KK, Burge CB, Bartel DP: Most mammalian mrnas are conserved targets of micrornas. Genome Res 2009;19:92-105.

-27 Grimson A, Farh KK, Johnston WK, Garrett-Engele P, Lim LP, Bartel DP: Microrna targeting specificity in mammals: Determinants beyond seed pairing. Mol Cell 2007;27:91-105.

28 Garcia DM, Baek D, Shin C, Bell GW, Grimson A, Bartel DP: Weak seed-pairing stability and high target-site abundance decrease the proficiency of lsy- 6 and other micrornas. Nat Struct Mol Biol 2011;18:1139-1146.

29 Grentzmann G, Ingram JA, Kelly PJ, Gesteland RF, Atkins JF: A dual-luciferase reporter system for studying recoding signals. RNA 1998;4:479-486.

-30 Hou J, Lin L, Zhou W, Wang Z, Ding G, Dong Q, Qin L, Wu X, Zheng Y, Yang Y, Tian W, Zhang Q, Wang C, Zhuang SM, Zheng L, Liang A, Tao W, Cao X: Identification of mirnomes in human liver and hepatocellular carcinoma reveals mir-199a/b-3p as therapeutic target for hepatocellular carcinoma. Cancer Cell 2011;19:232-243.

-31 Lv T, Yuan D, Miao X, Lv Y, Zhan P, Shen X, Song Y: Over-expression of lsd1 promotes proliferation, migration and invasion in non-small cell lung cancer. PLoS One 2012;7:e35065.

-32 Rajendiran S, Parwani AV, Hare RJ, Dasgupta S, Roby RK, Vishwanatha JK: Microrna-940 suppresses prostate cancer migration and invasion by regulating mien1. Mol Cancer 2014;13:250.

33 Song B, Ji W, Guo S, Liu A, Jing W, Shao C, Li G, Jin G: Mir-545 inhibited pancreatic ductal adenocarcinoma growth by targeting rig-i. FEBS Lett 2014;588:4375-4381.

34 Zambirinis CP, Miller G: Signaling via myd88 in the pancreatic tumor microenvironment: A double-edged sword. Oncoimmunology 2013;2:e22567.

-35 Ochi A, Graffeo CS, Zambirinis CP, Rehman A, Hackman M, Fallon N, Barilla RM, Henning JR, Jamal M, Rao R, Greco S, Deutsch M, Medina-Zea MV, Bin Saeed U, Ego-Osuala MO, Hajdu C, Miller G: Toll-like receptor 7 regulates pancreatic carcinogenesis in mice and humans. J Clin Invest 2012;122:4118-4129.

-36 Ochi A, Nguyen AH, Bedrosian AS, Mushlin HM, Zarbakhsh S, Barilla R, Zambirinis CP, Fallon NC, Rehman A, Pylayeva-Gupta Y, Badar S, Hajdu CH, Frey AB, Bar-Sagi D, Miller G: Myd88 inhibition amplifies dendritic cell capacity to promote pancreatic carcinogenesis via th2 cells. J Exp Med 2012;209:1671-1687. 